\title{
Volumetric abnormalities of thalamic subnuclei in medication-overuse headache
}

Zhiye Chen ${ }^{1,2,3}$, Zhihua Jia ${ }^{2}$, Xiaoyan Chen ${ }^{2}$, Mengqi Liu ${ }^{1,3}$, Shuangfeng Liu', Lin Ma ${ }^{1 *}$ and Shengyuan Yu ${ }^{2^{*}}$ (D)

\begin{abstract}
Background: The thalamus exerts a pivotal role in pain processing and cortical excitability control and a previous voxel-based morphometry study confirmed increased volume in bilateral thalamus in medication-overuse headache $(\mathrm{MOH})$. The aim of this study is to investigate altered thalamic subnuclei volume in $\mathrm{MOH}$ compared with normal controls, and to evaluate the relationship of each thalamic subnuclei volume with the clinical variables.

Methods: High resolution three-dimensional T1-weighted fast spoiled gradient recalled echo MR images were obtained from 27 patients with $\mathrm{MOH}$ and 27 normal controls (NC). Thalamic subnuclei templates were created based on Talairach template with MNI space transformation, and the individual thalamic subnuclei templates were generated by applying the deformation field from structural image segment to the thalamic subnuclei templates, and then individual thalamci subnuclei volume were calculated.
\end{abstract}

Results: The whole thalamus and each thalamic subnuclei presented increased volume compared with NC $(P<0.05)$. The correlation analysis demonstrated that the whole thalamus volume and each thalamic subnuclei volume showed a negative relationship with HAMD scores $(P<0.05)$, and no any correlation with HAMA, VAS score and disease duration $(P>0.05)$.

Conclusion: Increased gray matter volume in the whole thalamus and all the thalamus subnuclei may reflect central sensitization and higher-order of pain alteration in $\mathrm{MOH}$. These structural changes in the thalamus may also be influenced by mood disturbances related to the $\mathrm{MOH}$.

Keywords: Medication-overuse headache, Migraine, Thalamus, Magnetic resonance imaging

\section{Background}

Medication-overuse headache $(\mathrm{MOH})$ was defined as a headache occurring on 15 or more days per month developing as a consequence of regular overuse of acute or symptomatic headache medication for more than 3 months [1] . MOH has a prevalence of $0.6-2.0 \%$ in the general population $[2,3]$, and was associated with mood disorders in $27-85 \%$ and anxiety disorders in $61-83 \%$. $\mathrm{MOH}$ patients experience reduced quality of life compared with those who do not suffer from headaches [4]. A pre-existing headache disorder seems to be required to develop $\mathrm{MOH}$ [5]. It is well known that previous

\footnotetext{
*Correspondence: cjr.malin@vip.163.com; yusy1963@126.com

Zhiye Chen and Zhihua Jia contributed equally to this work.

Lin Ma and Shengyuan Yu contributed equally to this work.

'Department of Radiology, Chinese PLA General Hospital, 28 Fuxing Road, Beijing 100853, China

2Department of Neurology, Chinese PLA General Hospital, 28 Fuxing Road, Beijing 100853, China

Full list of author information is available at the end of the article
}

primary headaches such as migraine are the most important risk factors for the development of $\mathrm{MOH}$, $50 \%-70 \% \mathrm{MOH}$ have co-occurrence of migraine in population-based studies [6, 7]. Many psychosocial and socioeconomic factors which are prevailed in patients with chronic forms of headache are also associated with $\mathrm{MOH}$. However, the mechanism behind how chronic exposure to abortive medication leads to $\mathrm{MOH}$ remains unclear. Alteration of cortical neuronal excitability, central sensitization involving the trigeminal nociceptive system have been suggested to play a part in the pathophysiology of $\mathrm{MOH}$ [8].

The thalamus contains third-order trigeminovascular nociceptive neurons and exerts a pivotal role in pain processing and cortical excitability control $[9,10]$. Microstructural and functional alterations of the thalamus have been found in migraine patients [11, 12]. Significant volume reductions of the following thalamic 
nuclei densely connected to the limbic system were observed in migraineurs: central nuclear complex, anterior nucleus and lateral dorsal nucleus, supported that higher-order integration systems are altered in migraine [11]. Increased iron deposition and myelin content/ cellularity in the thalamus of migraine with aura patients compared with migraine without aura patients and healthy controls were found, may underlie abnormal cortical excitability control leading to cortical spreading depression and visual aura [13]. A voxelbased morphometry (VBM) study identified increased gray matter volume in bilateral thalamus in $\mathrm{MOH}$ patients [14]. Although it was demonstrated that periaqueductal gray (PAG) volume gain [15] and altered intrinsic functional connectivity architecture [16] were confirmed in $\mathrm{MOH}$ patients in our previous study, however, it was not known that how the thalamic subfields volume changed in $\mathrm{MOH}$ up to now.

Up to now, several documents had recognized that thalamic subnuclei were segmented based on diffusion tensor imaging [17, 18], and thalamic nuclei densely connected to the limbic system were observed in migraineurs [11]. Therefore, morphology analysis of thalamic subnuclei would provide more information in the understanding of neuromechanism of $\mathrm{MOH}$.

The main objective of the current study was to investigate the altered thalamic subnuclei volume in $\mathrm{MOH}$ compared with normal controls, and to further evaluate the relationship of each thalamic subnuclei volume with the clinical variables.

\section{Methods}

\section{Subjects}

This study was approved by the ethics committee of the Chinese PLA General Hospital, and written informed consent was obtained from the subjects according to the Declaration of Helsinki. Twenty-seven $\mathrm{MOH}$ patients were consecutively recruited from the headache center, Chinese PLA General Hospital. The included criteria of $\mathrm{MOH}$ included as follows: (1) All patients with both, $\mathrm{MOH}$ and migraine; (2) The diagnosis of $8.2 \mathrm{MOH}, 1.1$ and 1.2 migraine based on the International Classification of Headache Disorders, third Edition (beta version) (ICHD-III beta); (3) Without migraine preventive medication in the past 3 months. The excluded criteria included as follows: (1) With chronic disorders, including hypertension, diabetes mellitus, cardiovascular diseases, etc.; (2) With cranium trauma, psychotic disorder, and regular use of a psychoactive or hormone medication. Part of $\mathrm{MOH}$ patients were overlapping with our previous studies $[15,16]$. Twenty-seven normal controls (NCs) were recruited, who should never have any primary headache disorders or other types of headache in the past year, and had the same exclusion criteria with
$\mathrm{MOH}$ patients. Headache information were registered and evaluated in our headache database. All the patients were given with the Visual Analogue Scale (VAS) evaluation. Additionally, we used the Hamilton Anxiety Scale (HAMA) [19] scale to assess the anxiety, the Hamilton Depression Scale) [20] to assess the depression, and the Mini-mental State Examination (MMSE) [21] to assess the cognitive function of all the participants. MRI scans were taken in the interictal stage at least three days after a migraine attack for $\mathrm{MOH}$ patients. Alcohol, nicotine, caffeine, and other substances were avoided for at least $12 \mathrm{~h}$ before MRI examination.

\section{MRI acquisition}

MRI data were obtained by a conventional eight-channel quadrature head coil from a GE 3.0 T MR system (DISCOVERY MR750, GE Healthcare, Milwaukee, WI, USA). All subjects were instructed to lie in a supine position, and formed padding was used to limit head movement. An axial three-dimensional T1-weighted fast spoiled gradient recalled echo (3D T1-FSPGR) sequence was performed to acquire the brain structure images. The 3D T1-FSPGR parameters were listed as follows: $\mathrm{TR}($ repetition time $)=6.3 \mathrm{~ms}$, TE $($ echo time $)=2.8 \mathrm{~ms}$, flip angle $=15 \mathrm{o}$, FOV (field of view) $=25.6 \mathrm{~cm} \times 25.6 \mathrm{~cm}$, Matrix $=256 \times 256$, NEX (number of acquisition) $=1$ ]. All the subjects were performed the same imaging protocols, and the subjects with structural damage would be excluded.

\section{Image processing}

Image processing mainly included the following steps: (1) Convert Talairach template [22] into MNI space, and the thalamic subnuclei templates were created using rest software [23]. The thalamic subnuclei [11] included following subregions: left/right ventral posterior lateral nucleus (L_VPL/R_VPL), left/right ventral posterior medial nucleus (L_VPM/R_VPM), left/right dorsomedial nucleus (L_DM/R_DM), left/right ventral lateral nucleus (L_VL/R_VL), left/right ventral anterior nucleus (L_VA/ R_VA), and left/right anterior nucleus (L_AN/R_AN). (Fig. 1). (2) The individual structural images were segmented by the new segment tool embedded in SPM 12 software (http://www.fil.ion.ucl.ac.uk/spm), and the inverse deformation field was generated (iy_subjectID.nii). Then, the standard thalamic subnuclei were applied with the inverse deformation with pullback strategy, which would generate the individual thalamic subnuclei masks [15] (Fig. 2). Each individual thalamic subnucleus segmentations were visually inspected to confirm anatomical accuracy by one experienced radiologist. (3) The volume of individual thalamic subnuclei were measured by ITK-SNAP (V3.6.0) software (http://www.itksnap.org/ pmwiki/pmwiki.php). 


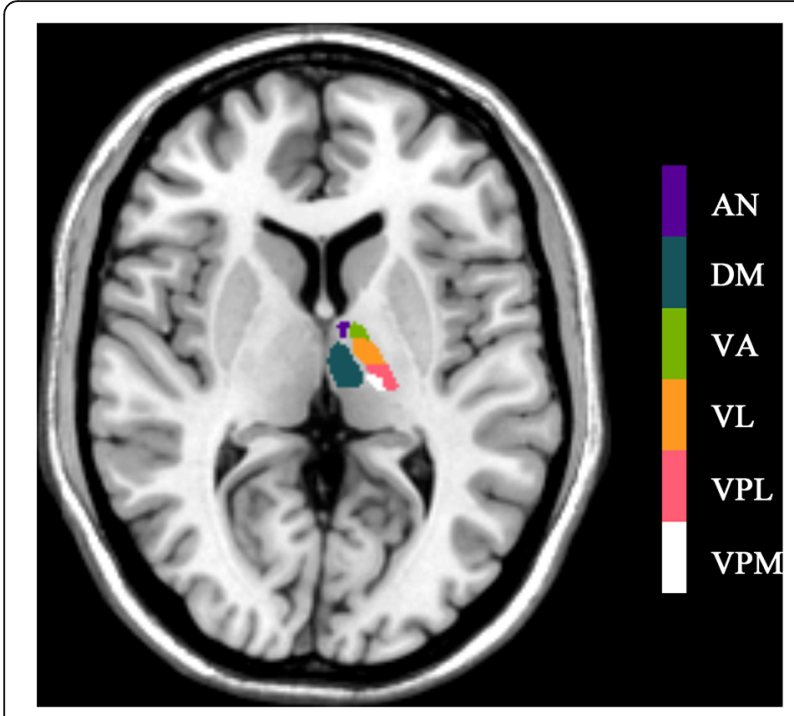

Fig. 1 The standard thalamic subnuclei templates were created according to Talairach template. AN, anterior nucleus; DM, doromedial nucleus; $V A$, ventral anterior nucleus; $V L$, ventral lateral nucleus; VPL, ventral posterior lateral nucleus; VPM, ventral posterior medial nucleus

\section{Statistical analysis}

The statistical analysis was performed by using PASW Statistics 18.0. The age, MMSE, HAMD, and HAMA were performed with independent samples $\mathrm{T}$ test, and sex was performed with Chi-Square test. The significance differences of whole thalamus and thalamic subnuclei volume were computed using analysis of covariance with the age and sex as covariates between

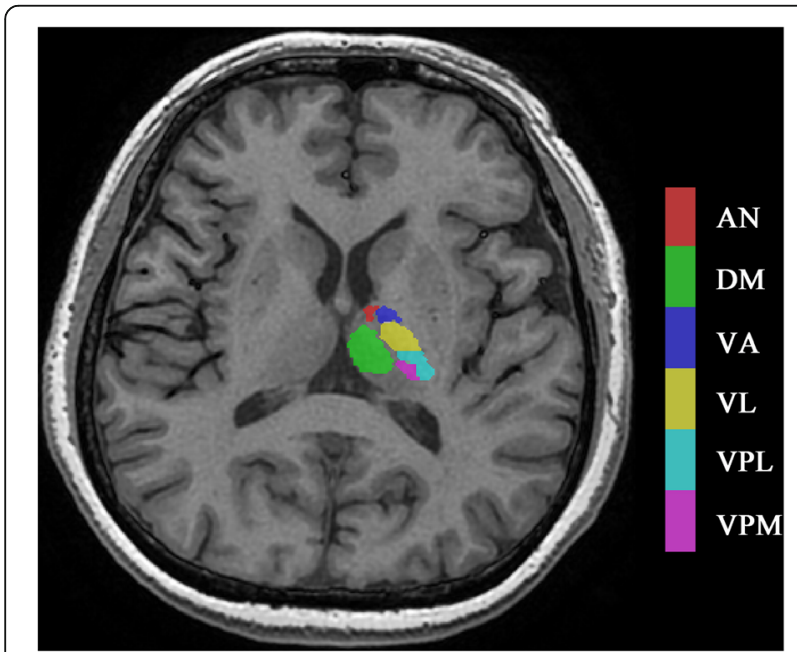

Fig. 2 The individual thalamic nuclei were generated by applying the inverse deformation with pullback strategy to the standard thalamic subnuclei. AN, anterior nucleus; DM, doromedial nucleus; VA, ventral anterior nucleus; VL, ventral lateral nucleus; VPL, ventral posterior lateral nucleus; VPM, ventral posterior medial nucleus
$\mathrm{MOH}$ group and NC group. The Pearson's correlation analysis was applied between thalamic volume and the clinical variables (including disease duration, VAS) in $\mathrm{MOH}$. Significant difference was set at a $P$ value of $<0.05$.

\section{Results}

Comparison of clinical characteristics between $\mathrm{MOH}$ and NC

The current study included $27 \mathrm{MOH}$ patients (F/ $M=20 / 7)$ and 27 normal controls $(F / M=19 / 8)$. The age, sex and MMSE showed no significant difference between $\mathrm{MOH}$ and $\mathrm{NC}(P>0.05)$. There was a significant HAMD and HAMA between MOH (20.85 \pm 12.67 and $17.70 \pm 8.63)$ and $\mathrm{NC}(7.32 \pm 4.26$ and $9.78 \pm 2.91)$ $(P<0.05)($ Table 1$)$.

\section{Comparison of thalamic subnuclei volume between $\mathrm{MOH}$} and NC

Table 2 demonstrated that all the thalamic subnuclei presented increased volume in $\mathrm{MOH}$ compared with $\mathrm{NC}$ $(P<0.05)$. Bilateral whole thalamus also showed increased volume in $\mathrm{MOH}\left(\mathrm{L}_{-} \mathrm{T}, 3.365 \pm 0.291 \mathrm{ml}\right.$, R_T,3.312 $\pm 0.288 \mathrm{ml})$ compared with $\mathrm{NC}\left(\mathrm{L} \_\mathrm{T}\right.$, $\left.3.237 \pm 0.249 \mathrm{ml}, \mathrm{R} \_\mathrm{T}, 3.190 \pm 0.241 \mathrm{ml}\right)(P<0.05)$ (Fig. 3).

\section{Correlation analysis between thalamic subnuclei volume} and the clinical variable

Figure 4 demonstrated that all the thalamic subnuclei volume were significantly negatively related with HAMD score $(P<0.05)$, and there were not significant relationship between all the thalamic subnuclei and the other clinical variables including HAMA, VAS and disease duration $(P>0.05)$ (Table 3$)$.

\section{Discussion}

Our study aimed to identify morphological changes of thalamic subnuclei in $\mathrm{MOH}$ and try to reveal more

Table 1 The clinical characteristics of the subjects

\begin{tabular}{lllll}
\hline & $\mathrm{MOH}$ & $\mathrm{NC}$ & T value & $P$ value \\
\hline Num(F/M) & $27(20 / 7)$ & $27(19 / 8)$ & $0.092^{\mathrm{a}}$ & 0.761 \\
Age & $39.93 \pm 9.75$ & $43.04 \pm 10.82$ & 2.007 & 0.272 \\
MMSE & $27.41 \pm 3.74$ & $28.19 \pm 1.00$ & 2.007 & 0.302 \\
HAMD & $20.85 \pm 12.67$ & $7.32 \pm 4.26$ & 2.008 & 0.000 \\
HAMA & $17.70 \pm 8.63$ & $9.78 \pm 2.91$ & 2.007 & 0.000 \\
DD & $18.07 \pm 9.85$ & $\mathrm{NA}$ & $\mathrm{NA}$ & $\mathrm{NA}$ \\
VAS & $8.26 \pm 1.46$ & $\mathrm{NA}$ & $\mathrm{NA}$ & $\mathrm{NA}$ \\
\hline
\end{tabular}

${ }^{a}$ Chi-square test. $\mathrm{MOH}$ medication-overuse headache, $N C$ normal control, $D D$ disease duration, VAS Visual Analogue Scale, HAMA Hamilton Anxiety Scale, HAMD Hamilton Depression Scale, MMSE Mini-mental State Examination, NA not available 
Table 2 The volume comparison of thalamic subnuclei $(\mathrm{ml})$ between $\mathrm{MOH}$ and $\mathrm{NC}$

\begin{tabular}{lllll}
\hline & MOH & NC & F value & $P$ value \\
\hline L_AN & $0.195 \pm 0.017$ & $0.187 \pm 0.015$ & 6.788 & 0.012 \\
L_DM & $1.164 \pm 0.106$ & $1.123 \pm 0.093$ & 4.627 & 0.036 \\
L_VA & $0.324 \pm 0.027$ & $0.311 \pm 0.023$ & 6.974 & 0.011 \\
L_VL & $1.056 \pm 0.090$ & $1.014 \pm 0.076$ & 7.570 & 0.008 \\
L_VPL & $0.375 \pm 0.033$ & $0.360 \pm 0.027$ & 7.546 & 0.008 \\
L_VPM & $0.253 \pm 0.022$ & $0.243 \pm 0.018$ & 7.087 & 0.010 \\
L_T & $3.365 \pm 0.291$ & $3.237 \pm 0.249$ & 6.474 & 0.014 \\
R_AN & $0.182 \pm 0.016$ & $0.175 \pm 0.013$ & 6.657 & 0.013 \\
R_DM & $1.845 \pm 0.112$ & $1.143 \pm 0.095$ & 4.529 & 0.038 \\
R_VA & $0.319 \pm 0.027$ & $0.306 \pm 0.022$ & 8.365 & 0.006 \\
R_VL & $0.997 \pm 0.083$ & $0.958 \pm 0.069$ & 7.607 & 0.008 \\
R_VPL & $0.393 \pm 0.034$ & $0.379 \pm 0.028$ & 6.059 & 0.017 \\
R_VPM & $0.236 \pm 0.021$ & $0.229 \pm 0.017$ & 4.937 & 0.031 \\
R_T & $3.312 \pm 0.288$ & $3.190 \pm 0.241$ & 6.210 & 0.016
\end{tabular}

$L$ left, $R$ right, $A N$ anterior nucleus, $D M$ dorsomedial nucleus, $V A$ ventral anterior nucleus, $V L$ ventral lateral nucleus, VPL ventral posterior lateral nucleus, VPM ventral posterior medial nucleus, $T$ thalamus

information about the neuromechanism of $\mathrm{MOH}$. In our study, psychiatric evaluation revealed that the majority of patients had comorbid psychiatric conditions, containing both anxiety and depressive disorders, which is accordant with epidemiologic studies [24, 25]. A previous study showed $\mathrm{MOH}$ patients have a greater risk of suffering from anxiety and depression than episodic migraine, and psychiatric disorders occurred significantly more often before the transformation from migraine into $\mathrm{MOH}$ than after [26]. It deduced that these disorders may be a risk factor for the evolution of migraine into $\mathrm{MOH}$. Another follow-up study identified several risk

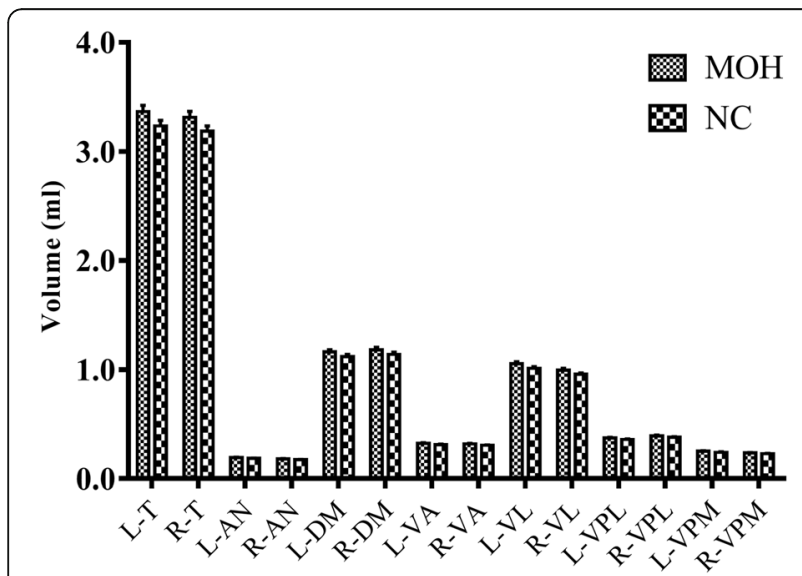

Fig. 3 The mean volume of thalamic subnuclei in $\mathrm{MOH}$ and $\mathrm{NC}$. $\mathrm{L}$, left; R, right; AN, anterior nucleus; DM, doromedial nucleus; VA, ventral anterior nucleus; VL, ventral lateral nucleus; VPL, ventral posterior lateral nucleus; VPM, ventral posterior medial nucleus factors for $\mathrm{MOH}$ among people with chronic headache, including increased Hospital Anxiety and Depression Scale score [27]. However, depression and anxiety disorders are associated with both migraine and nonmigrainous headache, and this was related to the headache frequency rather than headache diagnosis in another research, so the relationship between psychiatric disorders and $\mathrm{MOH}$ may be comobidity [28]. The causeeffect relationship needs further longitudinal study.

Consistent with the previous study [14], we found increased whole thalamus volume bilaterally in the $\mathrm{MOH}$. An increase in GMV may reflect structural brain plasticity as a result of exercise and learning [29]. Gray matter volume increase in the thalamus has also been found in chronic pain conditions such as back pain [30] and chronic post-traumatic headache [31]. Increased GMV in the thalamus might reflect central sensitization in chronic pain states. However, studies about the thalamic subnuclei volume in these chronic pain conditions have not been found. If the morphological abnormalities of thalamic subnuclei are specific to $\mathrm{MOH}$ or if the morphological abnormalities of thalamic can be normalized as cephalic, extra-cephalic pressure-pain thresholds and pain-related cortical potentials in $\mathrm{MOH}$ patients after withdrawal of the overused medication needs further study $[31,32]$. Unlike the specific thalamic subnuclei decreases observed in migraineurs [11], all the thalamic subnuclei presented increased volume in $\mathrm{MOH}$. Each thalamus is divided into the following subnuclei according to the inner medullary plate (including plate core): anterior nucleus (AN), dorsomedial nucleus (DM), ventral anterior nucleus (VA), ventral lateral nucleus (VL), ventral posterior lateral nucleus (VPL) and ventral posterior medial nucleus (VPM). AN of the thalamus is a key component of the hippocampal system for episodic memory. Via its connections with the anterior cingulate and orbitomedial prefrontal cortex, the AN may also involve in emotional and executive functions [33]. Affective and anxiety disorders prevailed in patients with chronic forms or transform of headache and substance use than in patients with migraine alone [34]. Decreased AN volume in migraineurs may be related to the psychiatric disorders in migraine patients and suggest that the central reorganization after repeated, long-term nociceptive signaling. Increased volume of AN in our study may suggest pre-existed morphological abnormalities in $\mathrm{MOH}$. Somatosensory-related thalamic structures can be broadly divided into lateral and medial subdivisions (VPL and VPM), which receive sensory inputs from the spinal cord or medulla to the thalamus directly through the spinothalamic tract or trigeminothalamic tract [35]. VPL and VPM then project to the dorsal part of thalamus and then sends axon projections to the cerebral cortex for a complete sensory transmission [36]. 

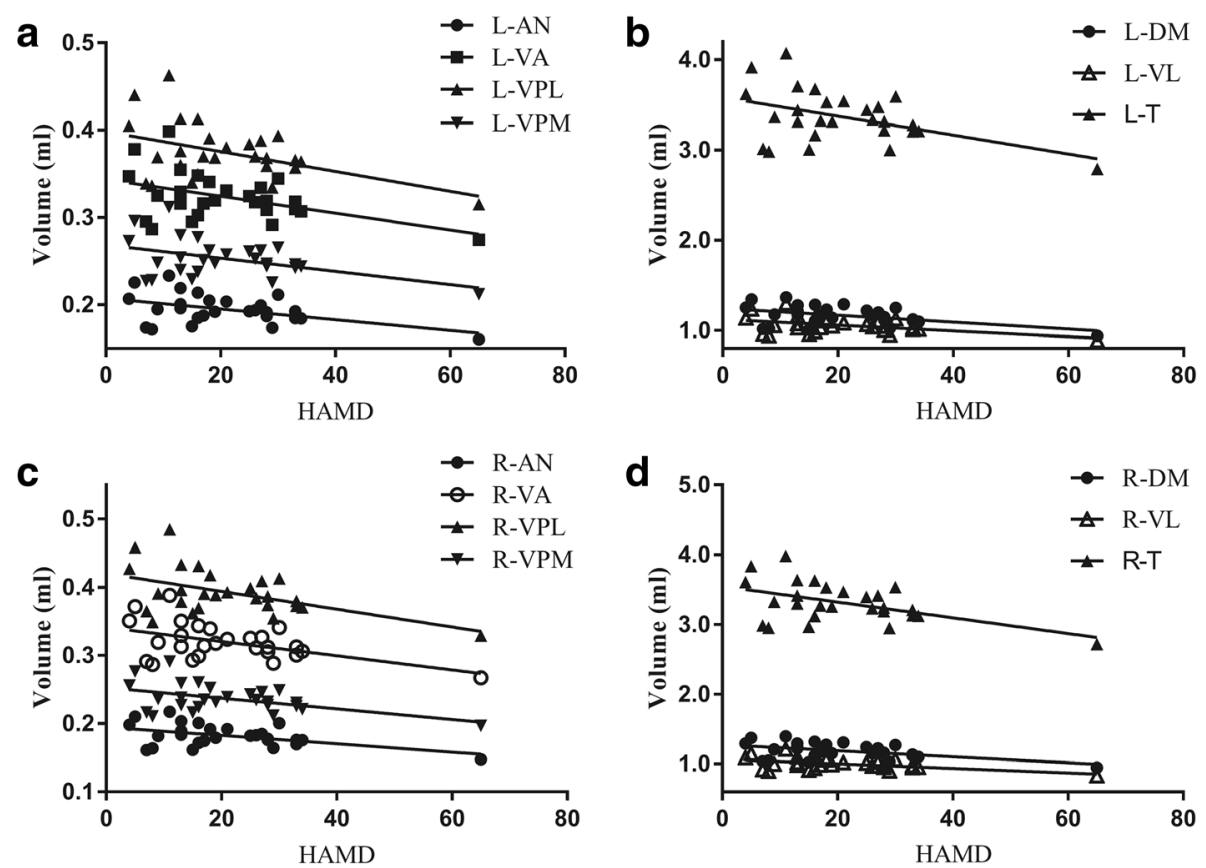

Fig. 4 The scatter plot between thalamic subnuclei volume and the HAMD score (a and $\mathbf{b}$, left thalamic subnuclei; $\mathbf{c}$ and $\mathbf{d}$, right thalamic subnuclei). $\mathrm{L}$, left; $\mathrm{R}$, right; $\mathrm{AN}$, anterior nucleus; $\mathrm{DM}$, doromedial nucleus; $\mathrm{VA}$, ventral anterior nucleus; $\mathrm{VL}$, ventral lateral nucleus; VPL, ventral posterior lateral nucleus; VPM, ventral posterior medial nucleus; T, thalamus; HAMD, Hamilton Depression Scale

Increased gray matter volume in DM, VPL and VPM may indicate higher-order of pain are altered in $\mathrm{MOH}$.

In our study, we did not find a relation between the volumes of thalamic nuclei and clinical features, such as VAS or the duration of the disorder. It suggests that increased gray matter volume in thalamus may relate to the genetic background of patients with $\mathrm{MOH}$. We observed negative associations between HAMD scores and gray matter volume in all the thalamus subnuclei in patients, suggesting that these structural changes may also

Table 3 The correlation of thalamic subnuclei volume with the clinical variables

\begin{tabular}{|c|c|c|c|c|c|c|c|c|}
\hline & \multicolumn{2}{|l|}{ HAMD } & \multicolumn{2}{|l|}{ HAMA } & \multicolumn{2}{|l|}{ VAS } & \multicolumn{2}{|l|}{ DD } \\
\hline & $r$ & $P$ value & $r$ & $P$ value & $r$ & $P$ value & $r$ & $P$ value \\
\hline L_AN & -0.469 & 0.016 & -0.159 & 0.439 & 0.002 & 0.991 & -0.018 & 0.929 \\
\hline L_DM & -0.466 & 0.017 & -0.171 & 0.404 & 0.025 & 0.902 & 0.071 & 0.724 \\
\hline L_VA & -0.467 & 0.016 & -0.192 & 0.347 & -0.073 & 0.718 & -0.009 & 0.966 \\
\hline L_VL & -0.468 & 0.016 & -0.186 & 0.363 & -0.069 & 0.733 & -0.005 & 0.981 \\
\hline L_VPL & -0.460 & 0.018 & -0.178 & 0.384 & -0.099 & 0.623 & 0.026 & 0.897 \\
\hline L_VPM & -0.453 & 0.020 & -0.161 & 0.434 & -0.087 & 0.668 & 0.035 & 0.863 \\
\hline$L_{-} T$ & -0.471 & 0.015 & -0.180 & 0.380 & -0.037 & 0.856 & 0.028 & 0.889 \\
\hline R_AN & -0.491 & 0.011 & -0.165 & 0.420 & 0.027 & 0.892 & -0.013 & 0.948 \\
\hline R_DM & -0.502 & 0.009 & -0.205 & 0.316 & 0.014 & 0.946 & 0.077 & 0.701 \\
\hline R_VA & -0.512 & 0.008 & -0.229 & 0.261 & -0.058 & 0.775 & 0.018 & 0.931 \\
\hline R_VL & -0.514 & 0.007 & -0.217 & 0.288 & -0.064 & 0.753 & 0.037 & 0.853 \\
\hline R_VPL & -0.506 & 0.008 & -0.215 & 0.292 & -0.109 & 0.589 & 0.052 & 0.796 \\
\hline R_VPM & -0.494 & 0.010 & -0.200 & 0.329 & -0.108 & 0.592 & 0.055 & 0.786 \\
\hline R_T & -0.513 & 0.007 & -0.213 & 0.297 & -0.037 & 0.853 & 0.052 & 0.798 \\
\hline
\end{tabular}

$L$ left, $R$ right, $A N$ anterior nucleus, $D M$ dorsomedial nucleus, $V A$ ventral anterior nucleus, $V L$ ventral lateral nucleus, VPL ventral posterior lateral nucleus, VPM ventral posterior medial nucleus, $T$ thalamus 
be influenced by mood disturbances related to the disorder [37].

\section{Conclusions}

In conclusion, increased gray matter volume in the whole thalamus and all the thalamus subnuclei may reflect central sensitization and higher-order of pain alteration in $\mathrm{MOH}$. These structural changes in the thalamus may also be influenced by mood disturbances related to the $\mathrm{MOH}$. Whether the observed morphological abnormalities in $\mathrm{MOH}$ can be reversed after withdrawal of the overused medication remains unclear.

\section{Abbreviations}

AN: Anterior nucleus; DM: Dorsomedial nucleus; $\mathrm{MOH}$ : Medication-overuse headache; NC: Normal controls; VA: Ventral anterior nucleus; VL: Ventral lateral nucleus; VPL: Ventral posterior lateral nucleus; VPM: Ventral posterior medial nucleus

\section{Acknowledgments}

This work was supported by the Special Financial Grant from the China Postdoctoral Science Foundation (2014 T70960) and the Foundation for Medical and health Sci \& Tech innovation Project of Sanya (2016YW37)

\section{Authors' contributions}

Category 1: (a) Conception and Design: L M; SYY (b) Acquisition of Data: ZYC; MQL; SFL; XYC. (c) Analysis and Interpretation of Data: ZYC Category 2: (a) Drafting the Article: ZYC, ZHJ. (b) Revising It for Intellectual Content: LM; SYY. All authors read and approved the final manuscript.

\section{Competing interests}

The authors declare that they have no competing interests.

\section{Publisher's Note}

Springer Nature remains neutral with regard to jurisdictional claims in published maps and institutional affiliations.

\section{Author details}

'Department of Radiology, Chinese PLA General Hospital, 28 Fuxing Road, Beijing 100853, China. ${ }^{2}$ Department of Neurology, Chinese PLA General Hospital, 28 Fuxing Road, Beijing 100853, China. ${ }^{3}$ Department of Radiology, Hainan Branch of Chinese PLA General Hospital, Sanya 572013, China.

Received: 27 June 2017 Accepted: 31 July 2017

Published online: 14 August 2017

\section{References}

1. Headache Classification Committee of the International Headache S (2013) The international classification of headache disorders, 3rd edition (beta version). Cephalalgia 33:629-808

2. Yu S, Liu R, Zhao G, Yang X, Qiao X, Feng J et al (2012) The prevalence and burden of primary headaches in China: a population-based door-to-door survey. Headache 52:582-591

3. Evers S, Marziniak M (2010) Clinical features, pathophysiology, and treatment of medication-overuse headache. Lancet Neurol 9:391-401

4. Lanteri-Minet M, Duru G, Mudge M, Cottrell S (2011) Quality of life impairment, disability and economic burden associated with chronic daily headache, focusing on chronic migraine with or without medication overuse: a systematic review. Cephalalgia 31:837-850

5. Bahra A, Walsh M, Menon S, Goadsby PJ (2003) Does chronic daily headache arise de novo in association with regular use of analgesics? Headache 43:179-190

6. Bigal ME, Lipton RB (2008) Excessive acute migraine medication use and migraine progression. Neurology 71:1821-1828

7. Kristoffersen ES, Lundqvist C (2014) Medication-overuse headache: a review. J Pain Res 7:367-378
8. Bongsebandhu-phubhakdi S, Srikiatkhachorn A (2012) Pathophysiology of medication-overuse headache: implications from animal studies. Curr Pain Headache Rep 16:110-115

9. Borsook D (2012) Neurological diseases and pain. Brain 135:320-344

10. Poulet JF, Fernandez LM, Crochet S, Petersen CC (2012) Thalamic control of cortical states. Nat Neurosci 15:370-372

11. Magon S, May A, Stankewitz A, Goadsby PJ, Tso AR, Ashina M et al (2015) Morphological abnormalities of thalamic subnuclei in migraine: a multicenter MRI study at 3 tesla. J Neurosci 35:13800-13806

12. Afridi SK, Giffin NJ, Kaube H, Friston KJ, Ward NS, Frackowiak RS, Goadsby PJ (2005) A positron emission tomographic study in spontaneous migraine. Arch Neurol 62:1270-1275

13. Granziera C, Daducci A, Romascano D, Roche A, Helms G, Krueger G, Hadjikhani N (2014) Structural abnormalities in the thalamus of migraineurs with aura: a multiparametric study at 3 T. Hum Brain Mapp 35:1461-1468

14. Riederer F, Marti M, Luechinger R, Lanzenberger R, von Meyenburg J, Gantenbein AR et al (2012) Grey matter changes associated with medication-overuse headache: correlations with disease related disability and anxiety. World J Biol Psychiatry 13:517-525

15. Chen Z, Chen X, Liu M, Liu S, Ma L, Yu S (2017) Volume gain of periaqueductal gray in medication-overuse headache. J Headache Pain. 18:12

16. Chen Z, Chen X, Liu M, Dong Z, Ma L, Yu S (2017) Altered functional connectivity architecture of the brain in medication overuse headache using resting state fMRI. J Headache Pain. 18:25

17. Wiegell MR, Tuch DS, Larsson HB, Wedeen VJ (2003) Automatic segmentation of thalamic nuclei from diffusion tensor magnetic resonance imaging. Neurolmage 19:391-401

18. Duan Y, Li X, Xi Y (2007) Thalamus segmentation from diffusion tensor magnetic resonance imaging. Int J Biomed Imaging 2007:90216

19. Maier W, Buller R, Philipp M, Heuser I (1988) The Hamilton anxiety scale: reliability, validity and sensitivity to change in anxiety and depressive disorders. J Affect Disord 14:61-68

20. Hamilton M (1967) Development of a rating scale for primary depressive illness. Br J Soc Clin Psychol 6:278-296

21. Galea M, Woodward M (2005) Mini-mental state examination (MMSE). Aust Physiother 51:198

22. Lancaster JL, Woldorff MG, Parsons LM, Liotti M, Freitas CS, Rainey L et al (2000) Automated Talairach atlas labels for functional brain mapping. Hum Brain Mapp 10:120-131

23. Song $X W$, Dong ZY, Long XY, Li SF, Zuo XN, Zhu CZ et al (2011) REST: a toolkit for resting-state functional magnetic resonance imaging data processing. PLoS One 6:e25031

24. Francoise Radat MD, Dina Sakh MD, Gina Lutz MD, Amrani ME, Maurice Ferreri MD, Marie-Germaine Bousser MD (1999) Psychiatric comorbidity is related to headache induced by chronic substance use in Migraineurs. Headache 39:477-480

25. Cupini LM, De MM, Costa C, Mancini M, Eusebi P, Sarchielli P, Calabresi P (2009) Obsessive-compulsive disorder and migraine with medicationoveruse headache. Headache 49:1005-1013

26. Radat F, Creac'h C, Swendsen JD, Lafittau M, Irachabal S, Dousset V, Henry P (2005) Psychiatric comorbidity in the evolution from migraine to medication overuse headache. Cephalalgia 25:519-522

27. Hagen $K$, Linde M, Steiner TJ, Stovner LJ, Zwart JA (2012) Risk factors for medication-overuse headache: an 11-year follow-up study. The NordTrondelag Health Studies Pain 153:56-61

28. Zwart JA, Dyb G, Hagen K, Odegard KJ, Dahl AA, Bovim G, Stovner $\sqcup$ (2003) Depression and anxiety disorders associated with headache frequency. The Nord-Trondelag Health Study Eur J Neurol 10:147-152

29. May A (2009) Morphing voxels: the hype around structural imaging of headache patients. Brain 132:1419-1425

30. Schmidt-Wilcke T, Leinisch E, Ganssbauer S, Draganski B, Bogdahn U, Altmeppen J, May A (2006) Affective components and intensity of pain correlate with structural differences in gray matter in chronic back pain patients. Pain 125:89-97

31. Ayzenberg I, Obermann M, Nyhuis P, Gastpar M, Limmroth V, Diener HC et al (2006) Central sensitization of the trigeminal and somatic nociceptive systems in medication overuse headache mainly involves cerebral supraspinal structures. Cephalalgia 26:1106-1114

32. Munksgaard SB, Bendtsen L, Jensen RH (2013) Modulation of central sensitisation by detoxification in $\mathrm{MOH}$ : results of a 12-month detoxification study. Cephalalgia 33:444-453 
33. Child ND, Benarroch EE (2013) Anterior nucleus of the thalamus: functional organization and clinical implications. Neurology 81:1869-1876

34. Antonaci F, Nappi G, Galli F, Manzoni GC, Calabresi P, Costa A (2011) Migraine and psychiatric comorbidity: a review of clinical findings. J Headache Pain 12:115-125

35. Ide S, Kakeda S, Korogi Y (2015) Anatomy of the thalamus. Brain Nerve 67:1459-1469

36. Yen CT, Lu PL (2013) Thalamus and pain. Acta Anaesthesiol Taiwanica $51: 73-80$

37. Hubbard CS, Khan SA, Keaser ML, Mathur VA, Goyal M, Seminowicz DA (2014) Altered brain structure and function correlate with disease severity and pain catastrophizing in migraine patients. eNeuro 1(e20):14

\section{Submit your manuscript to a SpringerOpen ${ }^{\odot}$ journal and benefit from:}

- Convenient online submission

- Rigorous peer review

- Open access: articles freely available online

- High visibility within the field

- Retaining the copyright to your article

Submit your next manuscript at $\gg$ springeropen.com 